\title{
Physiological performance and growth of Viburnum tinus L. on phytoremediated sediments for plant nursing purpose
}

\author{
Francesca Ugolini ${ }^{(1)}$, Costanza \\ Calzolari ${ }^{(1)}$, Giuseppe Mario \\ Lanini $^{(1)}$, Luciano Massetti ${ }^{(1)}$, \\ Francesco Sabatini ${ }^{(1)}$, Fabrizio \\ Ungaro $^{(1)}$, Stefania Damiano ${ }^{(2)}$, \\ Carlos Garcia Izquierdo ${ }^{(3)}$, \\ Cristina Macci ${ }^{(4)}$, Grazia \\ Masciandaro ${ }^{(4)}$
}

\begin{abstract}
Sediments are fundamental resources for productive activities like plant nursing, which are also likely to be responsible of their loss. In contrast, other activities like the dredging of canals and waterways involve the extraction and continuous accumulation of sediments. Most dredged sediments are polluted, and need to be stocked and transported to landfills, with extremely high costs for transport and management. To address these problems, a low-cost remediation methodology was previously developed to decontaminate sediments which were tested for use in plant nursery field plantations located in Pistoia (Italy). The phytoremediated sediments were mixed in percentages of $33 \%$ and $50 \%$ with alluvial soil, which itself was used as control. We studied the characteristics of these mixtures, and the physiological response and growth of Viburnum tinus L. grown on each substrate, as well as its corresponding root ball. Substrates with sediments showed quick water infiltration and no waterlogging, in sharp contrast to what was observed in autumn in the control. Despite a rainy summer, $V$. tinus demonstrated a good acclimation to the different substrates, showing the lowest leaf water potentials in mixed substrates and no signs of stress. No differences in leaf carbon assimilation or transpiration were observed among substrates, while in late August plants grown on substrates with sediments showed a higher performance index for energy conservation from photons absorbed by PSII to the reduction of intersystem electron acceptors. In the $50 \%$ mixture, there was also an enhancement of electron transport from PSII to PSI. Moreover, no differences in growth and biomass were found. Plants in all substrates showed some thin-root mortality, likely due to the persistent rainfall, though a higher number of plants with dead roots was observed in control. Thanks to the dense and fibrous root apparatus of $V$. tinus, the mixture with $33 \%$ sediments produced satisfactory results even for the root ball, resulting in less deformation and a lower breakage percentage.
\end{abstract}

Keywords: Biomass, Field Plantations, Leaf Gas Exchanges, Plant Nursing, PSII Efficiency, Root Balls, Sediments.

ties, that can be also responsible of their depletion. For instance, the estimate of soil loss in plant nursing (especially due to the extraction of plants from field plantations)

\section{Introduction}

Sediments are a dynamic and essentia part of water basins, as well as fundamental resources for many productive activi- is about 5.2 millions cubic meters every year in Europe (Marzialetti $P$, personal communication). The net loss of soil at the basin level, however, may be moderated to the extent that this material is replenished using agricultural soil.

In contrast, other productive activities such as transport on waterways are so constrained by the accumulation of sediments that regular dredging is required to safeguard ship passage. According to another estimate, about 200 millions cubic meters of sediments are dredged every year in Europe, of which $65 \%$ are contaminated by heavy metals, hydrophobic organic compounds and hydrocarbons (Salomons \& Brils 2004). Contaminated dredged sediments have to be stocked in confined disposal facilities, and then either transported at enormous cost to landfills according to the European Waste Framework Directive (Directive 2008/98/EC), or transformed (Netzband et al. 2002, Colombo et al. 2012). 
The European Life+ project CleanSed ("Innovative integrated methodology for the use of decontaminated river sediments in plant nursing and road building") addresses these two issues by applying an effective methodology (developed in the Agriport project) for the decontamination and amendment of sediments (Iannelli et al. 2010, Doni et al. 2013), and testing the remediated sediments for the plant nursery sector.

The Agriport methodology showed effective results regarding the decontamination of sediments dredged from the Navicelli canal (Pisa) and Livorno harbour. Heavy metals and petroleum hydrocarbons were removed from these soils by (a) modifying their physical and chemical properties with the addition of sandy soil (30\% by volume) and a layer of compost, and (2) applying phytoremediation for two years with a combination of Mediterranean species. Afterwards, during the Cleansed project, the phytoremediated sediments were treated with land farming. The whole process was found effective in the removal of all contaminants, meeting the legal limits for industrial and commercial use (Doni et al. 2013, Masciandaro et al. 2015).

Based on this experience, we hypothesize that decontaminated sediments using the methodologies described above could replace the agricultural soil that is typically used to recover the soil lost in field-plantation nurseries. To test the suitability of such phytoremediated sediments, an experimental plan was set up and implemented in Pistoia, a province leader of plant nursing in Italy.

The aim of the study was to assess the physical, chemical and hydraulic properties of different substrates with varying percentages of phytoremediated sediments mixed with alluvial soil of the Pistoia plain, and to assess the growth performance of commonly used ornamental shrub species such as Viburnum tinus L.

\section{Materials and methods}

\section{Experimental design}

The experiment was set up in the spring 2014 at the Center for Experimental Plant
Nursing (Ce.Spe.Vi.) in Pistoia (Italy), which is a prominent center for plant nursing, especially for trees and shrubs in field plantations. The area is highly suitable to this sector because of its climate and soil characteristics. The climate is Mediterranean semi-continental, with maximum and minimum temperatures of $31.6^{\circ} \mathrm{C}$ in August and $2.2^{\circ} \mathrm{C}$ in January, respectively, and an average annual rainfall of about $1200 \mathrm{~mm}$ (climate series 1981-2010 - http://www.lamma. rete.toscana.it/clima-e-energia/climatologia (clima-pistoia).

The alluvial soil of the Pistoia plain, used in the experimental setup for control plots, is generally composed of loamy silt, with poor structural stability, high water retention and tendency to compaction.

Five cubic meters of sediments dredged from the Navicelli canal (Pisa, Italy) were decontaminated using the Agriport methodology, until heavy metal concentrations reached values below the legal limits for industrial and civil use (Dlgs. 152/2006, D.M. 161/2012 and Dlgs. 217/2006 - Doni et al. 2013). Land farming was then applied during the Cleansed project, to further lower the contaminant concentrations (Masciandaro et al. 2015). The phytoremediated sediments were then mixed with the alluvial soil of the Pistoia plain that served in its original form as the control $(\mathrm{CTL})$, in percentages of 33\% (T33) and 50\% (T50) by volume.

The three soil mixtures (CTL, T33 and T50) were arranged in six wooden-frame boxes (two plots each) of $3 \mathrm{~m}^{3}$ ( $3 \mathrm{~m}$ long, $2 \mathrm{~m}$ wide, $0.5 \mathrm{~m}$ deep) and insulated from the ground with non-permeable fabric. In each plot, 24 one-year-old plants ( 8 per species) of three ornamental evergreen shrub species (Photinia $\times$ fraseri var. Red Robin, Eleagnus macrophylla L., and Viburnum tinus L.) were planted in May 2014 at $50 \mathrm{~cm}$ distance from each other, according the traditional planting pattern. However, since Photinia $\times$ fraseri and Eleagnus macrophylla showed similar physiological response and final biomass across the three substrates, in this paper we present only the results for Viburnum tinus.

An irrigation system with drip emitters (one per plant) delivered from 0.5 to $1 \mathrm{~L}$ of water per day. Fertilization was done on July 20, using $50 \mathrm{~g}$ of Osmocote $8 \mathrm{M}(16 \mathrm{~N}$ 11P-10K +2MgO) per plant.

\section{Weather conditions}

Weather parameters were recorded every 15 minutes at the Meteorological station in Ce.Spe.Vi. (long. $10^{\circ} 54^{\prime} \mathrm{E}$, lat. $43^{\circ} 56^{\prime} \mathrm{N}$, 60 m a.s.l.) equipped with a CR10 data logger (Campbell Scientific Campbell Park, Shepshed, Leicestershire, UK) and sensors for the main parameters. Summer 2014 recorded $50 \%$ more rainfall than the longterm climatic average, with very short dry periods; in particular, July was the wettest month with $187.6 \mathrm{~mm}$ of rain. The monthly mean temperature was around $23{ }^{\circ} \mathrm{C}$ from June to August whilst the maximum air temperatures were rarely above $35^{\circ} \mathrm{C}$, except in June (Fig. 1).

\section{Physical, chemical and hydrological characteristics of the substrates}

The phytoremediated sediments were characterized by a sandy loam texture (USDA classification) and the texture of the three substrates was determined taking three random samples of soil from each plot. The particle size analysis was performed using a pipette procedure (Indorante et al. 1990). Bulk density was also measured by taking three samples of 10 $\mathrm{cm}^{3}$ per plot from the upper $10 \mathrm{~cm}$, and recording the dry weight of the soil by volume after drying at $70^{\circ} \mathrm{C}$ for 72 hours.

For chemical analyses, three samples of soil were taken randomly at a depth of 10 $\mathrm{cm}$ from each substrate. The dried samples were sent to the Ionomics Service of the CEBAS-CSIC (Murcia, Spain). The $\mathrm{pH}$ and electrical conductivity (EC) were measured in deionized water (1:2.5 and 1:5 w/v, respectively). Macro and micro nutrient determination was done in samples digested using a high-performance microwave reaction with $\mathrm{HNO}_{3}: \mathrm{H}_{2} \mathrm{O}_{2}(4: 1, \mathrm{v} / \mathrm{v}$ - Ultraclave, Milestone, Shelton, CT, USA) and then analyzed with inductively coupled plasma-optical emission spectrometry (ICP-OES), in a Thermo ICAP 6000SERIES model. Carbon and nitrogen content were determined using a Flash 1112 series EA carbon/nitrogen analyzer.

$$
\mathrm{T}\left({ }^{\circ} \mathrm{C}\right)
$$

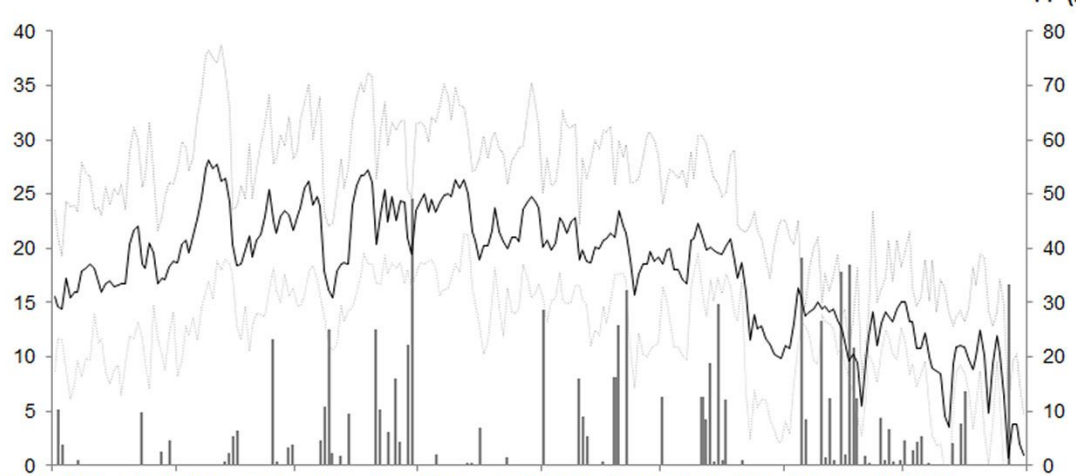

01/05/2014 $01 / 06 / 2014 \quad 01 / 07 / 2014 \quad 01 / 08 / 2014 \quad 01 / 09 / 2014 \quad 01 / 10 / 2014 \quad 01 / 11 / 2014 \quad 01 / 12 / 2014$
$\mathrm{PP}(\mathrm{mm})$

Fig. 1 - Weather conditions during the experimental period. (PP): Rainfall; ( $T$ Mean): Mean Air Temperature; ( $T$ Min): Minimum Air Temperature; (T Max): Maximum Air Temperature. 
The hydrological properties of the substrates were investigated in terms of soil moisture and water infiltration. One automatic Decagon 5 TE sensor (5TE), positioned at a depth of $20 \mathrm{~cm}$ in each plot, recorded soil moisture every 10 minutes.

Once the substrates were stabilized (October 2014), the constant head water infiltration was measured using the Guelph permeameter (Reynolds et al. 2002).

\section{Leaf water potential}

The plant water status was assessed through the measurement of leaf water potential using a pressure chamber (PMS Co., Corvallis, OR, USA). Pre-dawn ( $\Psi \mathrm{p})$ and minimum $(\Psi \mathrm{m}$, at the time of maximum transpiration) water potentials were measured on a sample of six fully expanded leaves in each substrate, one per plant, on May 20, June 18, July 18, August 18 and September 23. Leaves were detached from the third node from the apex of the central branches and readings were made immediately after detaching.

Following the Rambal's approach (Rambal 1992), daily oscillations of plant water status were represented as the difference between pre-dawn and minimum water potential $\left(\Delta \Psi=\Psi_{\mathrm{p}}-\Psi_{\mathrm{m}}\right)$, and the $\Delta \Psi / \Psi_{\mathrm{p}}$ relationship was analyzed using linear regression. The boundary straight line of the scatter of points identified the intercept on the $\Delta \psi$ axis (which represents the maximal daily amplitude of leaf water potential, when the soil water content is at field capacity and atmospheric evaporative demand is high) and the slope (which represents the relationship between predawn and minimum water potentials).

\section{Leaf gas exchange}

Leaf gas exchanges (photosynthesis $\mathrm{PN}$, and transpiration - ET) were measured on sunny days (May 16, July 9, July 31, August 31) at 10-11 a.m. with PAR (photosynthetically active radiation) $>1000 \mu \mathrm{mol}$ $\mathrm{m}^{-2} \mathrm{~s}^{-1}$. The measurements were taken on six fully expanded leaves (one per plant) in each substrate, chosen from the third node from the apex of the central branches, using a CIRAS-1 Infrared Gas Analyser (PPSystem, Hitchin, UK).

\section{Chlorophyll a fluorescence}

Chlorophyll a fluorescence was measured with a PEA (Plant Efficiency Analyzer, Hansatech, Instruments Ltd., King's Lynn, UK) at 10 a.m., on a sample of 16 fully expanded leaves per substrate (two clips per plant), chosen from the third node from the apex of the central branches, on July 18, July 31, August 31. Leaves were dark-adapted for 25 min with leaf clips, and direct fluorescence was then detected during $5 \mathrm{~s}$ of exposure to actinic light. Data were downloaded using the Winpea 32 v.1.00 software (Hansatech, Instruments Ltd., King's Lynn, UK) and processed in a Biolyzer 3.0 (JIPTest Analysis Program v.3.0, Laboratory of Bioenergetics, University of Geneva). The rising fluorescence transients were induced by red light (peak at $650 \mathrm{~nm}$ ) of $3000 \mu \mathrm{mol}$ photons $\mathrm{m}^{-2} \mathrm{~s}^{-1}$ provided by an array of six light emitting diodes; they were recorded for $1 \mathrm{~s}$, starting from $50 \mu \mathrm{s}$ after the onset of illumination, with 12-bit resolution. The fluorescence induction curve from $F_{0}$ to $F_{m}$ in dark-adapted samples is known as the "fluorescence transient" and its analysis is formalized in the JIP-test (Strasser et al. 2000, 2004). The different bands and steps of this polyphasic transient are labeled as: $\mathrm{O}(50 \mu \mathrm{s}$ in the JIP-test represents $F_{0}$, i.e., initial fluorescence), J (2 $\mathrm{ms}$ ), I (30 ms) and P (peak or $F_{M}$, i.e., maximum fluorescence). To assess the photosystem efficiency, the following parameters were then calculated:

- $\mathrm{Fv} / \mathrm{Fm}\left(\Phi_{\mathrm{PO}}\right)$ : maximum quantum yield of PSII primary photochemistry, which expresses the probability that an absorbed photon will be trapped by the PSII reaction center (initial phase of the electron transport chain);

- I-P phase $\left(\Delta \mathrm{V}_{\text {I-P }}\right.$ - Oukarroum et al. 2009), which indicates the amplitude of the I-P phase, i.e., the efficiency of electron transport around PSI to reduce the final acceptors of the electron transport chain (i.e., ferredoxin and NADP) which will bring to the carboxylation;

- Performance Index $\left(\mathrm{Pl}_{\mathrm{ABS}}\right)$, which is the performance index for energy conservation of photons absorbed by PSII, through the electron transport chain, from PSII to PSI.

Comparisons between substrates were made, and the parameters expressed as treated/control ratios.

\section{Aboveground biomass and branching}

At the beginning of the experiment, in May 2014, the stem diameter and length of the main branch were taken on a sample of six plants per substrate, three per plot. In November 2014, the same sample was destroyed for assessing growth and biomass. Stem diameter and length of the main branch, leaf area (using Model Li-3000 leaf area meter, Lincoln, Nebraska, USA) and dry biomass of leaves, wood and roots (after drying at $70{ }^{\circ} \mathrm{C}$ until reaching a constant dry weight) were all measured.

Branching indexes were also calculated by measuring the number of branches and their length in each branch order, according to Carrillo-Mendoza et al. (2010) and Hättenschwiler et al. (1997).

\section{Root and root ball assessment}

One of the most important aspects in plant nursing is the protection of the roots when plants are extracted from soil for sale. Root quality has significant impact on the ability of plants to survive and grow after transplanting in landscape (Whiting \& O'Meara 2014). Bare roots quickly dehydrate when exposed to air, so that when field-grown plants are dug from the growing field, root ball and soil should be intact. To prevent the root ball from breaking, the roots are usually balled and wrapped with burlap. In the absence of a standardized form for root ball evaluation, we developed an evaluation form based on qualitative and quantitative parameters: soil moisture; deformation under a mechanical force applied (e.g., placing the root ball on the ground); root ball resistance to compression; percentage class of rupture; and presence of macrofauna. In November 2014, six root balls of $50 \mathrm{~cm}$ in diameter were extracted by hand and assessed immediately after extraction. Soil moisture was measured by the gravimetric method after mixing together subsamples of the substrate from the root balls. Root ball deformation was assessed using a qualitative 5-class scale: (5) it does not deform or break; (4) it is rather compact; (3): it breaks into a few aggregates; (2) it breaks into many aggregates; (1): it is completely deformed. Resistance to compression was assessed using a pocket penetrometer (ELE International, Bedfordshire, UK), by taking three measurements randomly on each root ball. The percentage of rupture was assessed using 4 classes: (1) more than $60 \%$; (2) from 30 to $60 \%$; (3) up to $30 \%$; (4) no rupture. The assessment of macrofauna involved counting the numbers of earth worms and presence/abscence of other invertebrates (e.g., pill-bugs).

Root analysis concerned the root system embedded in the root ball with a very limited part of external roots cut for root ball extraction. Root balls were soaked overnight in water to disperse soil aggregates and then washed by hand, taking the floating roots and cleaning them by applying water pressure over the whole root apparatus. Root analysis regarded the vitality of new thin roots (less than or equal to $1 \mathrm{~mm}$ diameter at mid-length) which were separated from the main roots. Three samples of new thin roots were randomly taken and assessed to determine their vitality (alive or dead) on the base of morphological criteria (colour, elasticity and resilience). For each plant, the number of dead new thin roots out of the total was determined and classified in percentage classes $(0 \% ;<5 \%$; 5 $25 \%$; $25-50 \%$; $50-75 \%$; $>75 \%$ ). Total root biomass was also measured after drying at 70 ${ }^{\circ} \mathrm{C}$ until reaching constant weight.

\section{Statistical analysis}

The statistical analysis was carried out using the software Statistica ver. 4.5 (StatSoft Inc., Tulsa, OK, USA). Departures from normality of the chemical properties of the three substrates, leaf gas exchanges, $\mathrm{Chl} a$ fluorescence parameters, plant biomass and growth parameters, and the resistance to penetration of the root ball in the three substrates were tested using the ShapiroWilk's test. ANOVA followed by Tukey's test for post-hoc comparison of means was then performed for identifying the statistical differences.

Regarding the root ball assessment, classes of deformation and classes of rup- 
Tab. 1 - Physical and chemical characteristics of the three substrates. (T33): 33\% phytoremediated sediments mixed with alluvial soil; (T50): $50 \%$ phytoremediated sediments mixed with alluvial soil; (CTL): $100 \%$ alluvial soil). Mean values and standard deviations are given. Different letters within the same row indicate significant differences between means of the three substrates after Tukey's test $(\mathrm{P}<0.05, \mathrm{~N}=3$ for each substrate).

\begin{tabular}{|c|c|c|c|}
\hline Parameter & T33 & T50 & CTL \\
\hline Clay:Silt:Sand & $6.6: 39.4: 54$ & $10.5: 34.4: 55.1$ & $10.3: 34.9: 54.8$ \\
\hline $\mathrm{pH}$ & $8.15 \pm 0.05^{b}$ & $8.06 \pm 0.02^{b}$ & $8.34 \pm 0.05^{\mathrm{a}}$ \\
\hline Electric Conductivity $\left(\mu \mathrm{S} \mathrm{cm}^{-1}\right)$ & $361.33 \pm 35.22^{b}$ & $597.33 \pm 49.81^{\mathrm{a}}$ & $75.50 \pm 3.16^{c}$ \\
\hline Total C (g/100g) & $2.70 \pm 0.03^{b}$ & $3.20 \pm 0.22^{\mathrm{a}}$ & $1.90 \pm 0.05^{c}$ \\
\hline Total N (g/100g) & $0.20 \pm 0.03^{\mathrm{a}}$ & $0.20 \pm 0.01^{\mathrm{a}}$ & $0.10 \pm 0.01^{b}$ \\
\hline $\mathrm{C}: \mathrm{N}$ & $17.60 \pm 3.30$ & $17.10 \pm 0.40$ & $14.30 \pm 1.40$ \\
\hline$P(g / 100 g)$ & $0.06 \pm 0.00^{\mathrm{a}}$ & $0.06 \pm 0.00^{\mathrm{a}}$ & $0.05 \pm 0.00^{\mathrm{b}}$ \\
\hline $\mathrm{K}(\mathrm{g} / 100 \mathrm{~g})$ & $1.00 \pm 0.01$ & $0.99 \pm 0.06$ & $0.96 \pm 0.10$ \\
\hline $\mathrm{Ca}(\mathrm{g} / 100 \mathrm{~g})$ & $1.65 \pm 0.01^{\mathrm{b}}$ & $2.29 \pm 0.13^{\mathrm{a}}$ & $0.63 \pm 0.05^{c}$ \\
\hline$M g(g / 100 g)$ & $1.06 \pm 0.09$ & $1.02 \pm 0.09$ & $1.00 \pm 0.14$ \\
\hline $\mathrm{S}(\mathrm{g} / 100 \mathrm{~g})$ & $0.14 \pm 0.00^{b}$ & $0.23 \pm 0.02^{\mathrm{a}}$ & $0.02 \pm 0.00^{c}$ \\
\hline $\mathrm{NO}_{3}^{-}\left(\mathrm{mg} \mathrm{L}^{-1}\right)$ & $9.10 \pm 0.27^{\mathrm{a}}$ & $9.80 \pm 0.29^{a}$ & $7.10 \pm 0.79^{b}$ \\
\hline $\mathrm{SO}_{4}^{2-}\left(\mathrm{mg} \mathrm{L}^{-1}\right)$ & $120.10 \pm 7.98^{b}$ & $264.70 \pm 28.73^{a}$ & $3.70 \pm 0.94^{c}$ \\
\hline $\mathrm{PO}_{4}^{3-}\left(\mathrm{mg} \mathrm{L}^{-1}\right)$ & $0.10 \pm 0.03^{b}$ & $0.00 \pm 0.00^{c}$ & $0.30 \pm 0.08^{a}$ \\
\hline Bulk density $\left(\mathrm{mg} \mathrm{m}^{-3}\right)$ & $1.10 \pm 0.07^{b}$ & $1.06 \pm 0.05^{\mathrm{b}}$ & $1.15 \pm 0.08^{a}$ \\
\hline Water infiltration $\left(\mathrm{mm} \mathrm{hr}^{-1}\right)$ & $5.50 \pm 2.60^{\mathrm{b}}$ & $61.00 \pm 27.00^{\mathrm{a}}$ & $0.14 \pm 0.11^{c}$ \\
\hline
\end{tabular}

ture in each substrate were determined by the calculation of the weighted average, on the basis of the number of occurrences of each class.

For each plant, the average percentage of dead new thin roots was calculated and attributed to a percentage class. Then, in each substrate, the percentage class of new thin dead roots was identified by the calculation of the weighted average on the base of the number of occurrences of each class. The differences between substrates were found by comparing the frequency of the percentage classes, using a $\chi^{2}$ test for 2-way tables. $\chi^{2}$ values were compared with critical $\chi^{2}$ values at $\alpha=0.05$ and 1 degree of freedom. The same test was also used for assessing the presence of invertebrates like pill-bugs in each root ball extracted.

Tables and figures report mean values, standard deviations and significance with $P$-values.

\section{Results}

Physical, chemical and hydrological characteristics of the substrates

The physical, chemical and hydrological characteristics of the three substrates are summarized in Tab. 1. The three substrates were characterized by a sandy loam texture (USDA classification) with CTL richer in silt compared to T33 and T50, which were richer in clay. In addition, T33 and T50 had a lower bulk density than CTL, which in contrast was more compact, and they were also more heterogeneous and looser in structure due to the presence of clay aggregates (reaching $>10 \mathrm{~cm}$ in diameter).

In terms of $\mathrm{pH}$, all three substrates were alkaline, with the highest values in CTL, though it had the lowest concentration of Ca. EC showed higher values in the presence of phytoremediated sediments, especially in T50. Both treatments (T33 and T50) had a good $\mathrm{C}: \mathrm{N}$ ratio, but were poor in macronutrients like $\mathrm{P}$ and $\mathrm{K}$.
Regarding the hydraulic properties, water infiltration was very quick in T50 and T33, whereas CTL showed the lowest values. In summertime (after an initial inconsistency required changing the position of two sensors), the daily soil moisture at a depth of $20 \mathrm{~cm}$ (Fig. 2) was found to be slightly higher in CTL and $\mathrm{T}_{50}$ (ranging between $16.4 \%$ and $31.1 \%$ in CTL and between $13.7 \%$ and $27 \%$ in T50) than in T33 (range: $12.1 \%$ to $22.6 \%$ ), with a pattern more linked to the rain occurrence. In the fall, soil moisture showed the highest values in all substrates, reaching saturation and waterlogging in CTL (data not shown). Both T50 and T33 showed a slight decreasing trend after the peak on November $18^{\text {th }}$, and T33 had the lowest values.

\section{Plant physiological performances}

The lowest $\psi \mathrm{p}$ values were observed on July 18 , with significant differences between CTL and the sediment treatments ( $T 33$ and T50). The latter recorded the low-

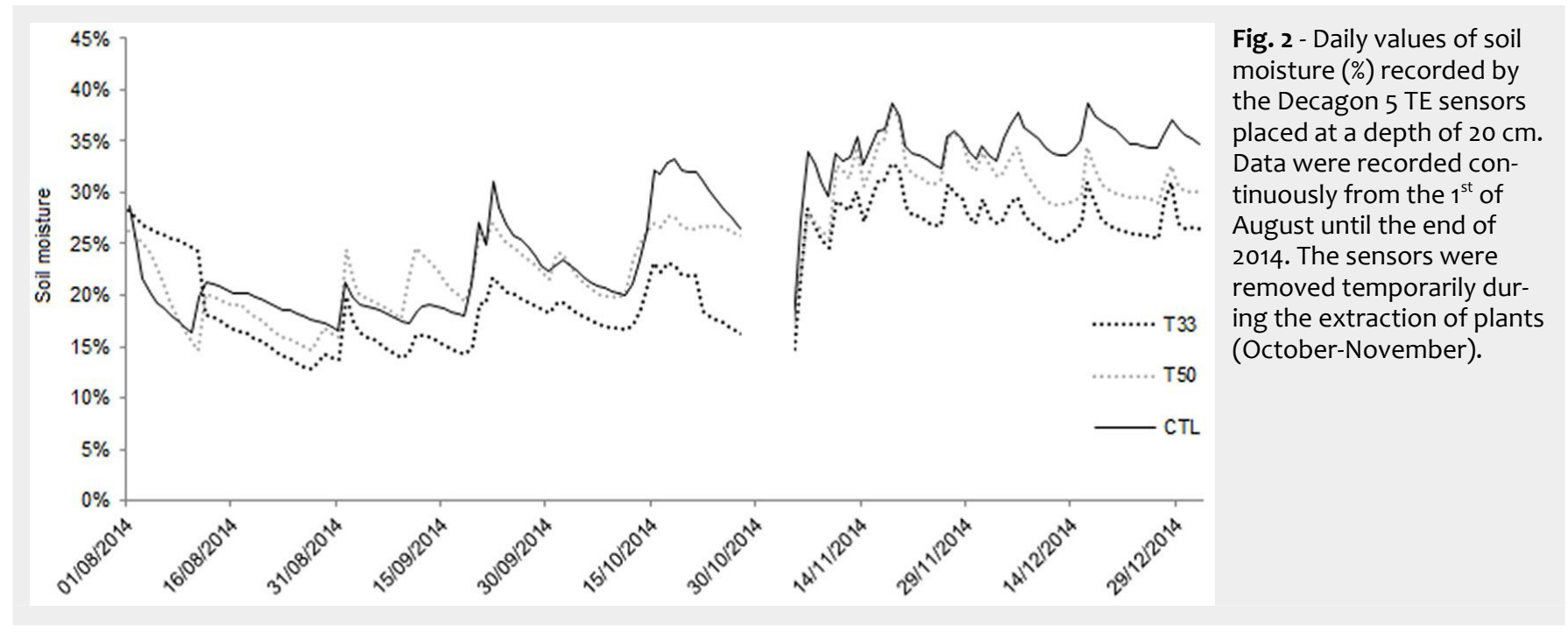




\section{A}

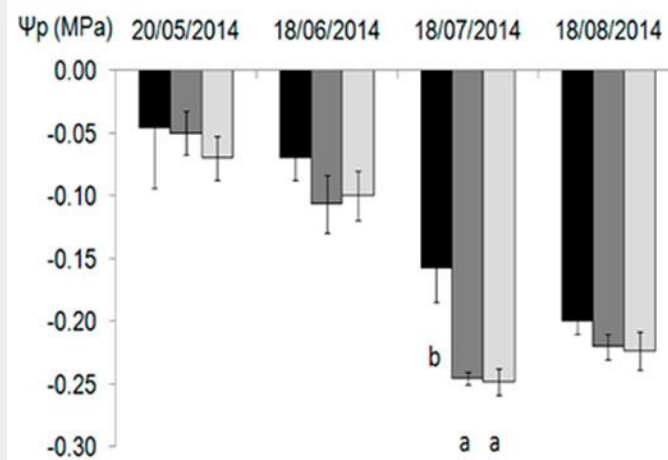

$\Psi_{\mathrm{phr}}$. 4-5 B

23/09/2014

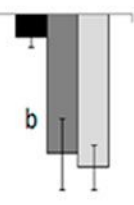

a a
$\psi_{\mathrm{m}}(\mathrm{MPa})$ 20/05/2014

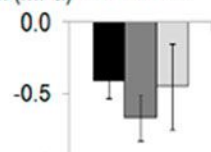

$-1.0$

$-1.5$

$-2.0$

$-2.5$
$\Psi_{\min }-\mathrm{hr} .13-14$

18/06/2014 18/07/2014 18/08/2014 23/09/2014
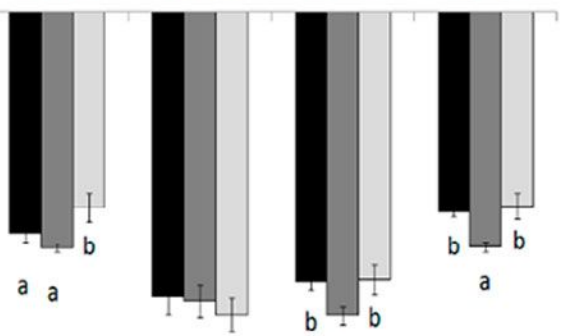

a

- CTL $\bullet T 33 \square T 50$

Fig. 3 - (A) Pre-dawn ( $\Psi$ p) and (B) minimum ( $\left.\Psi_{\mathrm{min}}\right)$ water potential in Viburnum tinus during the experiment. Mean values and standard deviations are shown for the three substrates (CTL, T33, T50). Significant differences resulted from the Tukey test at $P<0.05$ are shown by letters in each date of measurement $(\mathrm{N}=18)$.

est values (Fig. 3A), though on September $23^{\text {rd }}$ after a period of rain, values increased. The lowest values of $\Psi \mathrm{min}$ were -2.3 $\mathrm{MPa}$ in T50 (measured on July 18 ) and $-2.2 \mathrm{MPa}$ in T33 on August 18, in accordance with the lower soil moisture value at the time of measurement (Fig. 3B, Tab. 2).

In CTL V. tinus showed higher $\Psi p$ than in T33 and T50 and similar maximum values of $\Delta \Psi$ (e.g., the difference between pre-dawn and minimum water potential) in the three substrates. The relationship between $\Delta \Psi$ and $\Psi \mathrm{p}$ given by the regression analysis revealed a linear dependence in $\operatorname{CTL}(\Delta \Psi=$ $\left.2.65 \Psi \mathrm{p}+2.3, \mathrm{R}^{2}=0.45, \mathrm{P}=0.002\right)$ and T33 $\left(\Delta \Psi=5.7 \Psi \mathrm{p}+3.2, \mathrm{R}^{2}=0.68, \mathrm{P}=0.003\right)$, whilst in T50 the relationship was weak $\left(\Delta \Psi=-2.26 \Psi p+1.25, R^{2}=0.0654\right)$. The intercept of the upper boundary of the points, represented by a straight line, ranged between $3.6 \mathrm{MPa}$ in CTL to $5.6 \mathrm{MPa}$ in T33 with higher slopes in T33 and T50 (Tab. 3).

On each date, $V$. tinus showed similar photosynthesis as well as leaf transpiration in all substrates. The highest rates of photosynthesis were observed on July 31, compared to the previous dates $(P<0.05)$ and even compared to 31 August in T33 $(\mathrm{P}<$ 0.01). Leaf transpiration recorded higher values on July 18 and 31 in CTL and in T50, especially compared to August $31(\mathrm{P}<0.01$ Fig. 4).

No significant difference was found between the substrates on any given date of measurement for $\mathrm{F}_{0}, \mathrm{Fm}, \Phi_{\mathrm{PO}}, \Delta \mathrm{V}_{\mathrm{IP}}$ and $\mathrm{PI}_{\mathrm{ABS}}$. However in $\mathrm{T} 33$, in late August, $\mathrm{PI}_{\mathrm{ABS}}$ and

Tab. 2 - Soil moisture at the time of leaf water potential measurement, measured by Decagon 5 TE sensor (5TE), positioned at a depth of $20 \mathrm{~cm}$ in each plot. For each substrate the average value between two plots is given.

\begin{tabular}{llll}
\hline Measurement & CTL & T33 & T50 \\
\hline 18/08/2014 Hr. 4-5 & 20.1 & 16.3 & 18.7 \\
18/08/2014 Hr. 13-14 & 29.5 & 21.4 & 26.4 \\
23/09/2014 Hr. 4-5 & 20.2 & 16.2 & 18.4 \\
23/09/2014 Hr. 13-14 & 28.2 & 20.1 & 25.7 \\
\hline
\end{tabular}

Tab. 3 - Minimum absolute values of pre-dawn ( $\Psi$ p, MPa) and minimum leaf water potential $(\Psi \mathrm{m}, \mathrm{MPa})$, intercept value $\left(\Psi_{\max }, \mathrm{MPa}\right)$ and slope of the regression analysis between pre-dawn leaf water potential $(\Psi p)$ and the difference between predawn and minimum water potential for the three substrates $(\Psi)$, according Rambal's approach (Rambal 1992).

\begin{tabular}{lcccc}
\hline Substrate & $\boldsymbol{\Psi p}_{\mathrm{p}}$ & $\boldsymbol{\Psi m}_{\mathrm{m}}$ & Intercept & Slope \\
\hline CTL & -0.21 & -2.1 & 3.7 & -9.6 \\
T33 & -0.25 & -2.2 & 5.6 & -13.0 \\
T50 & -0.26 & -2.3 & 5.4 & -22.0 \\
\hline
\end{tabular}

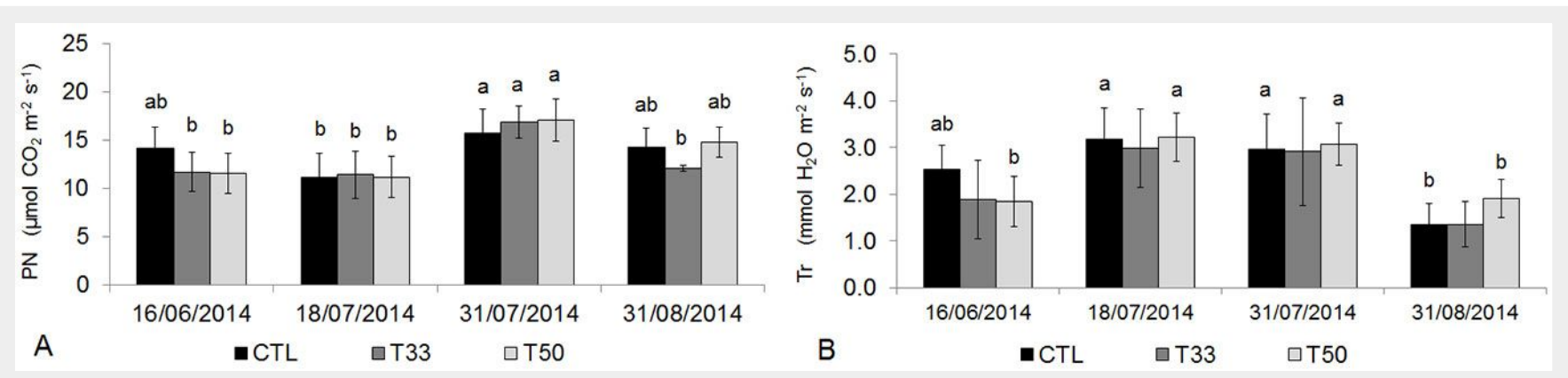

Fig. 4 - (A) Net photosynthesis (PN) and (B) transpiration (Tr) in Viburnum tinus during the experiment. Mean values and standard deviations are shown for the three substrates (CTL, T33, T50). Different small-capital letters indicate significant differences between means after Tukey's test ( $p<0.05, N=6$ in each substrate). No differences were found between substrates at the same date, while significant differences were detected between similar substrates at different dates. 


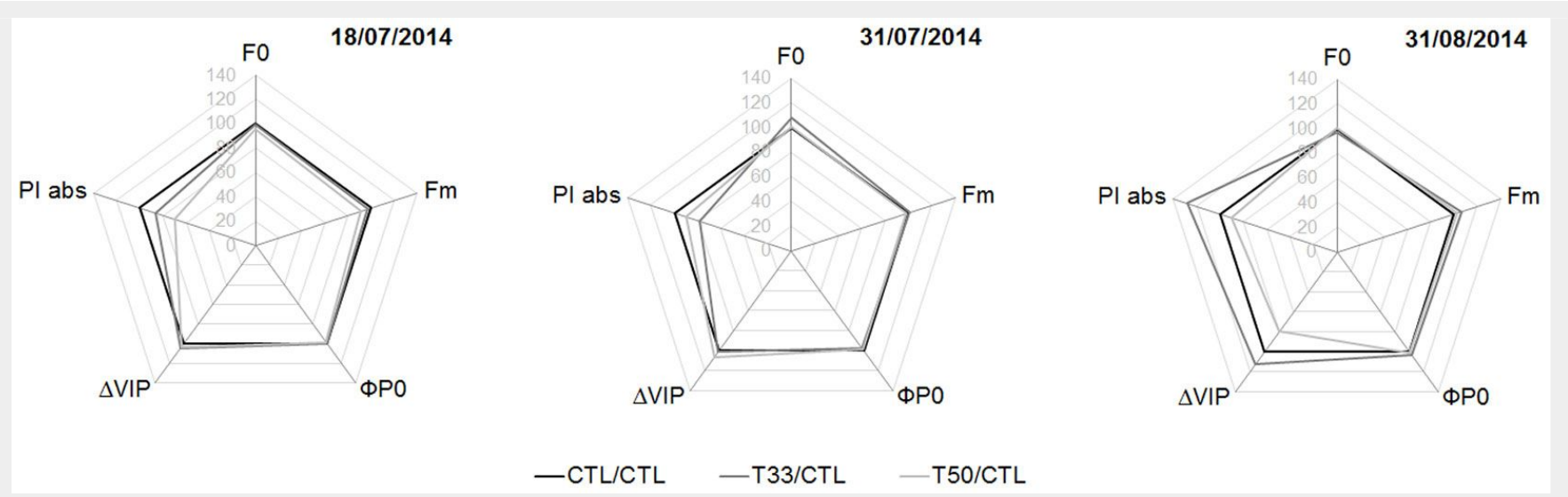

Fig. 5 - "Spider plot" of the parameters of direct fluorescence during the experiment, expressed as percentage relative to the control ( $C T L=100$, black polygon; $N=16$ in each substrate). $\left(F_{0}\right)$ : initial fluorescence; $(F m)$ : maximum fluorescence; $\left(\Phi_{P_{0}}\right)$ : maximum quantum yield of primary photochemistry in a dark-adapted leaf (i.e., probability of an absorbed photon to be trapped by the PSII reaction center); $\left(\Delta \mathrm{V}_{\mathrm{IP}}\right)$ : probability of a PSII trapped electron to be transferred to PSI acceptors (i.e., efficiency of electron transport around the PSI to reduce the final acceptors of the electron transport chain); ( $\mathrm{PI}_{\mathrm{ABS}}$ ): performance index of energy conservation from photons absorbed by PSII to the reduction of intersystem electron acceptors in the electron transport chain. See Tab. 3 for the significance of differences among substrates.

Tab. 4 - Level of significance of differences between parameter values in Fig. 5, during the experiment in summer. Tukey's test ( $\alpha=$ 0.05 ) was used for post-hoc comparison of means among substrates ( $\mathrm{N}=16$ for each date and substrate). Arrows indicate an increase $(\uparrow)$ or decrease $(\downarrow)$ of the parameter values at the date in the column heading, compared to the date in the row heading.

\begin{tabular}{|c|c|c|c|c|c|c|c|c|c|c|}
\hline \multirow{2}{*}{ Parameter } & \multirow{2}{*}{ Date } & \multicolumn{3}{|l|}{ CTL } & \multicolumn{3}{|l|}{ T33 } & \multicolumn{3}{|l|}{ T50 } \\
\hline & & $18 / 7$ & $31 / 7$ & $31 / 8$ & $18 / 7$ & $31 / 7$ & $31 / 8$ & $18 / 7$ & $31 / 7$ & $31 / 8$ \\
\hline \multirow[t]{3}{*}{ F0 } & $18 / 07$ & - & ns & ns & - & $<0.05 \uparrow$ & ns & - & ns & ns \\
\hline & $31 / 07$ & ns & 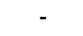 & ns & $<0.05$ & - & $<0.001 \downarrow$ & ns & - & ns \\
\hline & $31 / 08$ & ns & ns & - & ns & $<0.001 \uparrow$ & - & ns & ns & - \\
\hline \multirow[t]{3}{*}{$\mathrm{Fm}$} & $18 / 07$ & 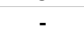 & ns & ns & - & ns & ns & - & ns & ns \\
\hline & $31 / 07$ & ns & - & ns & ns & - & ns & ns & - & ns \\
\hline & $31 / 08$ & ns & ns & - & ns & ns & - & ns & ns & - \\
\hline \multirow[t]{3}{*}{$\Delta \mathrm{V}_{\mathbb{P}}$} & $18 / 07$ & - & ns & ns & - & ns & ns & - & ns & ns \\
\hline & $31 / 07$ & ns & - & ns & ns & - & ns & ns & - & $<0.01 \uparrow$ \\
\hline & $31 / 08$ & ns & ns & - & ns & ns & - & ns & $<0.01 \downarrow$ & - \\
\hline \multirow[t]{3}{*}{$\Phi_{\mathrm{P} 0}$} & $18 / 07$ & - & ns & ns & - & ns & ns & - & ns & ns \\
\hline & $31 / 07$ & ns & - & ns & ns & - & ns & ns & - & ns \\
\hline & $31 / 08$ & ns & ns & - & ns & ns & - & ns & ns & - \\
\hline \multirow{3}{*}{$\mathrm{Pl}_{\mathrm{ABS}}$} & $18 / 07$ & - & ns & ns & - & ns & $<0.05 \downarrow$ & - & ns & ns \\
\hline & $31 / 07$ & ns & - & ns & ns & - & $<0.01 \uparrow$ & ns & - & $<0.05 \uparrow$ \\
\hline & $31 / 08$ & ns & ns & - & $<0.05 \uparrow$ & $<0.01 \downarrow$ & - & ns & $<0.05 \downarrow$ & - \\
\hline
\end{tabular}

peak on July $31(P<0.05$ with respect to Aboveground biomass and branching July 18$)$ and a decrease on August $31(P<$ 0.001 with respect to July 31$)$. On this date, $\mathrm{Pl}_{\mathrm{ABS}}$ was higher than on July 31 both in $\mathrm{T} 33$ $(P<0.01)$ and in T50 $(P<0.05)$. Again on August 31, but only in $T 50, \Delta \mathrm{V}_{\mathrm{IP}}$ showed the highest value $(P<0.01$ with respect to July 31- Tab. 4).
Aboveground biomass and branching
When comparing between the three substrates, $V$. tinus did not show differences in stem growth in terms of the initial and final size of the main shoot (diameter at the stem base and length) and the final biomass (leaf area, total biomass), but there was high variability within the samples.
Even branching indexes for number (Bl1) and length (BI2) of branches did not show statistical differences among the substrates (Tab. 5), among which CTL showed the highest internal variability, with larger mean values for Bl1 and smaller ones for $\mathrm{BI} 2$.

Tab. 5 - Growth and biomass parameters of $\mathrm{V}$. tinus in the three substrates. Mean values and standard deviations are given. $(\Delta \mathrm{H})$ : height difference of the main branch between May and October 2014; $(\Delta \varnothing)$ : difference of stem diameter at the base, between May and November 2014; (Branching index 1): number of branches in each order with respect to the previous order branch (Carrillo-Mendoza et al. 2010); (Branching index 2): ratio between the cumulative length of the secondary branches and that of the first order branch (Hättenschwiler et al. 1997). Tukey's test $(\alpha=0.05)$ was used for post-hoc comparison of means among substrates $(\mathrm{N}=6$ in each substrate). (ns): not significant.

\begin{tabular}{lcccccc}
\hline Substrate & $\begin{array}{c}\Delta \mathbf{H} \\
(\mathbf{c m})\end{array}$ & $\begin{array}{c}\Delta \emptyset \\
(\mathbf{c m})\end{array}$ & $\begin{array}{c}\text { Leaf Area } \\
\left(\mathbf{c m}^{2}\right)\end{array}$ & $\begin{array}{c}\text { Total Biomass } \\
(\mathbf{g})\end{array}$ & $\begin{array}{c}\text { Branching } \\
\text { Index 1 }\end{array}$ & $\begin{array}{c}\text { Branching } \\
\text { Index 2 }\end{array}$ \\
\hline CTL & $28.6 \pm 4.5$ & $0.4 \pm 0.1$ & $6599 \pm 2316$ & $176.9 \pm 50.0$ & $66.5 \pm 69.7$ & $18.4 \pm 17.7$ \\
T33 & $24.3 \pm 5.1$ & $0.5 \pm 0.1$ & $7215 \pm 1531$ & $238.3 \pm 62.3$ & $28.4 \pm 20.6$ & $45.8 \pm 28.1$ \\
T50 & $29.4 \pm 5.5$ & $0.5 \pm 0.2$ & $7182 \pm 2415$ & $198.8 \pm 59.8$ & $29.0 \pm 20.7$ & $41.8 \pm 38.2$ \\
Prob & ns & ns & ns & ns & ns & ns \\
\hline
\end{tabular}


Tab. 6 - Root ball and root assessment. (RUPT): Percentage of rupture; (RES): Resistance to penetration; (RW): Root dry biomass; (Depth): deepening depth of roots; ; (*): a minimum part of fine external roots has been lost during the root ball extraction. Different letters within the same column indicate significant differences between means of the three substrates after Tukey's test $(P<0.05, N=6$ in each substrate). For qualitative parameters, the weighted average was calculated on the basis of the number of occurrences of the classes in the point scale. The frequency of dead new thin roots in the substrates was compared using a $\chi^{2}$ test for 2-way tables $(\alpha=0.05, \mathrm{df}=1)$.

\begin{tabular}{|c|c|c|c|c|c|c|c|}
\hline Substrate & Root ball deformation & RUPT & $\begin{array}{c}\text { RES } \\
\left(\mathrm{Kg} \mathrm{cm}^{-2}\right)\end{array}$ & $\begin{array}{l}\mathrm{RW}^{*} \\
\text { (g) }\end{array}$ & $\begin{array}{l}\text { Depth } \\
(\mathrm{cm})\end{array}$ & $\begin{array}{l}\text { Dead fine } \\
\text { roots (\%) }\end{array}$ & $\begin{array}{c}\text { Plants with }>5 \% \\
\text { dead roots }(\%)\end{array}$ \\
\hline CTL & Rather compact & $<30 \%$ & $1.50 \pm 0.66^{a}$ & $54 \pm 4$ & $13.67 \pm 1.51$ & $18 \pm 8$ & 100 \\
\hline T33 & Rather compact & $<30 \%$ & $1.58 \pm 0.47^{\mathrm{a}}$ & $81 \pm 13$ & $16.50 \pm 2.35$ & $11 \pm 13$ & 50 \\
\hline T50 & Breaking in big aggregates & $>60 \%$ & $0.55 \pm 0.26^{b}$ & $53 \pm 30$ & $13.67 \pm 4.23$ & $15 \pm 18$ & 50 \\
\hline Prob & - & - & $<0.05$ & ns & ns & ns & $<0.005$ \\
\hline
\end{tabular}

Root ball and root assessment

When the root ball extraction was made, soil moisture was around $25-30 \%$. The root balls showed the presence of earthworms without differences among substrates (1.4 \pm 1.06 in CTL, $0.8 \pm 0.89$ in T33, $0.8 \pm 1.03$ in T50), whilst the presence of pill-bugs was observed only in CTL compared to T33 or $T_{50}\left(X_{[1]}^{2}=27.11, P<0.05\right)$. V. tinus showed rather compact root balls in CTL and T33, in which on average the breaking percentage was up to $30 \%$, whereas in T50, the root balls showed a tendency to break easily in aggregates (even larger than $10 \mathrm{~cm}$ in size). The resistance to penetration showed the same pattern, with significant difference between T50 (easy penetration) and the other substrates $(P<0.05)$.

$V$. tinus has an extremely dense root system, and in this experiment it deepened up to $15 \mathrm{~cm}$ in the substrate, with no difference between the three substrates. The assessment of new thin roots showed a certain percentage of dead new thin roots in all substrates, despite the fact that the frequency was higher in CTL (Tab. 6).

\section{Discussion}

Field-grown plant production presents many advantages, like low start-up costs and reduced maintenance during the growing period (Dunwell \& Vanek 2013), but it is responsible for a consistent loss of topsoil when plants are transplanted from the nursery to their final location. For instance, in Europe the loss of soil due to plant nursery production is estimated at around 5.6 million cubic meters every year (Marzialetti $\mathrm{P}$, personal communication). When new plantations are set up, suitable new soil is usually needed for augmenting the existing soil and improving its quality. In general, new soil is extracted from agricultural fields that undergo land use change.

In this experiment we tested the use of polluted river sediments, dredged from a waterway and remediated through lowcost and sustainable methodologies (Agriport and (leanSed), in nursery field-grown plant production. The Agriport methodology, followed by land-farming (during the Life+ Cleansed project), has proved to be effective in lowering the concentration of contaminants and producing a substrate suitable for agricultural purposes. In fact, these techniques stimulated the activation of microbial biomass (increase in biochemical activity) and reduced the concentration of heavy metals (Doni et al. 2013, 2015), and they similarly reduced the concentration of residual organic contamination (by 15\%), while increasing the homogenization of the substrate (Masciandaro et al. 2015). The remediated sediments, with levels of contaminants below the limits set by Italian Law 152/06, were then tested for fieldgrown nursery production.

We looked at the properties of substrates containing remediated sediments in different percentages ( $0 \%, 33 \%, 50 \%)$, mixed with alluvial soil from the plain of Pistoia where the experiment was set up (a region known for its high-volume nursery production and for the outstanding growth performance of its cultivated ornamental species). Because the remediated sediments were characterized not only by a loose structure and sandy loam texture but also by a high degree of heterogeneity in terms of aggregate size, the position of soil moisture sensors in these mixed substrates had to be changed at the beginning of the experiment. However, later on in the fall, low evaporation and wet ground due to the persistent rains caused waterlogging in the control but not in substrates with the phytoremediated sediments. The improved drainage properties of these substrates were also demonstrated by very high water infiltration rates in the two sediment-containing mixtures, as opposed to minimal rates in the control.

Regarding the physiological performance of $V$. tinus, the analysis of the water status showed that in substrates with sediments plants had the lowest values of $\Psi \mathrm{p}$ and $\Psi \mathrm{m}$ along with the lower values of soil moisture. From the analysis of the relationship between $\Delta \Psi$ and $\Psi$ p , we observed a strong correlation between the two parameters in T33 and CTL and higher values of the intercept $(\Delta \Psi$ is the maximal daily amplitude when the soil water content is at field capacity and the evaporative demand high) and slopes of the regression in T33 and T50. These results suggest likely higher transpiration rates (Rambal 1992, Borghetti et al. 2004), but also a greater control of leaf transpiration because at minimum changes in pre-dawn water potential the amplitude $\Delta \Psi$ approaches zero. This is defined as "regulatory behavior", which is typical of the xeric Mediterranean species (Hickman 1970, Rambal 1992).

However, the plants were not exposed to water deficit, and the irrigation and the rainy season provided ample water. Leaf gas exchanges (carbon absorption and water transpiration) that were measured in the morning (at lower evaporative demand compared to midday) also did not show differences between the three substrates. Leaf transpiration recorded the lowest values on August 31, though without changes in water use efficiency (data not shown). The ecological conditions in which the plants grow play an important role in the performance of the photosystem (Murata et al. 2007, Demmig-Adams et al. 2014). Indeed, it is known that high temperatures associated with water stress stimulate the photosystem efficiency through a quicker electron transport between PSII and PSI (Bussotti et al. 2012). However, in this study, plants were watered, and in addition the season was particularly rainy. The photochemical efficiency of $V$. tinus was similar in the three substrates. The polyphasic chlorophyll a fluorescence transient with OJIP steps, which gives information about the efficiency of PSII photochemistry, in general did not evidence abiotic stress conditions. $\Phi_{\mathrm{PO}}$ was on average around 0.75 in all substrates, similarly to other experiments (Fini et al. 2013), and it did not change throughout the summer. On August 31, plants grown in sediment mixtures also showed higher performance index values for energy conservation from photons absorbed by PSII to the reduction of intersystem electron acceptors, likely associated with a better energy transfer by open reaction centers at the PSII. In T50, there was also an enhancement of electron transport from PSII to PSI $\left(\Delta \mathrm{V}_{\mathrm{IP}}\right)$, connected to a quicker ability of ferredoxin reduction, used to reduce $\mathrm{NADP}+$ into NADPH essential for the Calvin cycle.

On that date, air temperature at the time of measurement was $29^{\circ} \mathrm{C}$, likely below the critical value limiting photosynthesis in Mediterranean species (Bussotti et al. 2014), and $\mathrm{CO}_{2}$ adsorption was similar to the previous dates. This, being associated with the enhanced electron transport as well as 
$\mathrm{PI}_{\mathrm{ABS}}$, would positively affect the $\mathrm{CO}_{2}$ fixation (Krall \& Edwards 1992, Van Heerden et al. 2007).

The long term effects of the physiological behavior are then noticeable on plant size and growth. The above-ground development is crucial for its growth and commercial purposes, as the below-ground apparatus and root ball guarantee plant survival at harvest and after transplanting (Davis \& Jacobs 2005, Gilman \& Sadowski 2014). V. tinus showed a good aboveground development, with fairly dense foliage and branching, with no difference between substrates. Moreover, V. tinus has a dense shallow root apparatus, likely with a large number of active root tips, which would favor regeneration and transplanting suc cess (Davis \& Jacobs 2005). Despite this, we observed mortality of thin roots $(<1 \mathrm{~mm}$ in diameter) in all substrates; the control recorded the highest number of plants with a greater percentage of dead roots, likely due to compaction and temporarily anoxic conditions (and maybe also related to the fact that the woody frame boxes probably did not facilitate water percolation). Moreover, a compact soil ball of fine texture may present in the landscape a texture interface that would affect water circulation, so that gradual texture changes would be preferable for minimizing water problems (Coder 2015).

Trees with fibrous root systems grow bet ter in a looser structure, and afterwards are more successful in transplanting than those with coarse roots due to a higher regeneration potential (Struve 2009). At the same time, a dense root apparatus reduces the level of root ball breakage. Root ball is important also to determine the depth level of the structural roots (Struve 2009), though it may interfere with the time new roots need to explore the soil outside the root ball (Harris \& Gilman 1993).

In this experiment, the substrates with sediments had a looser structure than the control, and showed a level of breakage of the root ball particularly high in T50 (with more than $60 \%$ of breakage). Root ball compaction is particularly important for preventing the loss of fine roots by mechanical injuries and desiccation in digging and preparing balled-and-burlapped plants, though the length of exposure to air between extraction and transplanting is also relevant (Harris \& Bassuk 1993, McKay 1997, Mena-Petite et al. 2001). Indeed, soil removal from a root system can result in a loss of up to $90 \%$ of absorbing roots (JackScott 2012, Hartmann et al. 2011, Kozlowski \& Davis 1975). Roots are extremely important because in close contact with soil, their loss and damage diminish the water uptake capability of plants (Watson \& Himelick 1997, Koeser \& Stewart 2008). However, the technique of planting bare root plants, together with accurately applying proper care, undoubtedly cheaper than transplanting a balled and burlapped plant or one in a container (Yang \& McBride 2003), has also reported positive results, with high rates of survival after transplanting (Hensley 1993, Bassuk 2000, Buckstrup \& Bassuk 2000), so that the sediments may be considered suitable for this kind of technique.

Finally, this study showed that a substrate with $33 \%$ remediated sediments mixed with alluvial soil characteristic of the Pistoia plain, resulted in conditions suitable for cultivating $V$. tinus. If we considered this percentage suitable also for other species (Ugolini et al. 2015), we could estimate for Pistoia province a soil recovery of 6001200 cubic meters per year, depending on the species cultivated. In addition, due to the loamy silt texture of the plain soil (ARPAT 2001), the remediated sediments would contribute to reducing the probability of anoxic conditions which impair the quality of the root systems.

\section{Conclusions}

This experiment focused on the use of phytoremediated sediments through the Agriport and Cleansed methodologies, in plant nursing for field-grown plantations. The remediated sediments, added in percentages of $33 \%$ and $50 \%$ by volume to a loam sandy soil with a higher content of silt (control), significantly improved water drainage. In the first year of growth, the species described here ( $V$. tinus) showed physiological performance and final biomass similar to the control. In mixed substrates as well in the control, the plants showed some root mortality, although in the control the frequency was higher. However, thanks also to the dense and fibrous root apparatus, a sediment concentration up to $33 \%$ proved satisfactory even for the root ball, in terms of compaction and likely breakage.

\section{Acknowledgements}

The project was funded by the European Commission under the programme Life+ 2013-2016 (LIFE12ENV/IT/00652). We thank Dr. Paolo Marzialetti and Nicola Petrucciani (Centro Sperimentale per il Vivaismo, Pistoia, Italy) for their valuable suggestions, logistical support and assistance with plantation.

\section{References}

ARPAT (2001). Valutazione dell'impatto ambientale delle pratiche vivaistiche e studio della vulnerabilità intrinseca della falda nel territorio pistoiese. [Environmental impact assessment of plant nursing and study of the intrinsic vulnerability of the water table in the Pistoia territory]. Osservatorio sul vivaismo, Comune di Pistoia, Pistoia, Italy, pp. 151. [in Italian]

Bassuk N (2000). Creating the urban forest: the bare root method. Cornell University, Ithaca, NY, USA, pp. 16.

Borghetti M, Magnani F, Fabrizio A, Saracino A (2004). Facing drought in a Mediterranean post-fire community: tissue water relations in species with different life traits. Acta Oecolog- ica 25: 67-72. - doi: 10.1016/j.actao.2003.11.004 Buckstrup MJ, Bassuk NL (2000). Transplanting success of balled and burlapped versus bareroot trees in the urban landscape. Journal of Arboriculture 26 (6): 298-308. [online] URL: http://www.actrees.org/files/Research/transpla nting_bareroot_vs_bb.pdf

Bussotti F, Kalaji MH, Desotgiu R, Pollastrini M, L oboda T, Bosa K (2012). Misurare la vitalità delle piante per mezzo della fluorescenza della clorofilla. [Measuring plants vitality through chlorophyll fluorescence]. Firenze University Press, Firenze, Italy, pp. 138. [in Italian]

Bussotti F, Ferrini F, Pollastrini M, Fini A (2014). The challenge of Mediterranean sclerophyllous vegetation under climate change: from acclimation to adaptation. Environmental and Ex perimental Botany 103: 80-98. - doi: 10.1016/j. envexpbot.2013.09.013

Carrillo-Mendoza O, Sherman WB, Chaparro JX (2010). Development of branching index for evaluation of peach seedlings using interspecific hybrids. Hortscience 45: 852-856.

Coder KD (2015). Chapter 7: site assessment and soil improvement. FOR 96, School of Forest Resources and Conservation Department, UF/ IFAS Extension, Gainesville, FL, USA, pp. 20. [online] URL: http:/ledis.ifas.ufl.edu/pdffiles/fr/ fro7100.pdf

Colombo V, Ghedini E, Gherardi M, Mani V, Sanibondi P, Vazquez B (2012). RF thermal plasma treatment of dredged sediments: vitrification and silicon extraction. Journal of Physics: Conference Series 406: 012039. - doi: 10.1088/17426596/406/1/012039

Davis AS, Jacobs DF (2005). Quantifying root system quality of nursery seedlings and relationship to outplanting performance. New Forests 30: 295-311. - doi: 10.1007/s11056-005-7480-y Demmig-Adams B, Stewart JJ, Adams IIIWW (2014). Multiple feedbacks between chloroplast and whole plant in the context of plant adaptation and acclimation to the environment. Philosophical Transaction of the Royal Society B 369: 20130244. - doi: 10.1098/rstb.20 13.0244

Doni S, Macci C, Peruzzi E, lannelli R, Ceccanti B, Masciandaro G (2013). Decontamination and functional reclamation of dredged brackish sediments. Biodegradation 24: 499-512. - doi: 10.1007/s10532-012-9606-1

Doni S, Macci C, Peruzzi E, lannelli R, Masciandaro $G$ (2015). Heavy metal distribution in a sediment phytoremediation system at pilot scale. Ecological Engineering 81: 146-157. - doi: 10.1016/j.ecoleng.2015.04.049

Dunwell W, Vanek S (2013). Field nursery production. University of Kentucky, Lexington, KY, USA, pp. 5. [online] URL: http://www.uky. edu/Ag/CCD/introsheets/field.pdf

Fini A, Mori J, Teani A, Burchi G, Ferrini F (2013). Evaluation of different shrub species for carbon uptake and pollution removal. ISA, Toronto, Canada, pp. 11. [online] URL: http:// www.isa-arbor.com/events/conference/procee dings/2013/FINI_ISA2013_shrubs_paper.pdf Gilman EF, Sadowski L (2014). Selecting quality trees from the nursery. ENG 1060, Urban Forest Hurricane Recovery Program series, School of Forest Resources and Conservation and the Environmental Horticulture Department, UF/ 
IFAS Extension, Gainesville, FL, USA, pp. 8. [online]

URL:

http://edis.ifas.ufl.edu/pdffiles/EP/EP31300.pdf Harris JR, Bassuk NL (1993). Tree planting fundamentals. Journal of Arboriculture 19 (2): 64-70. [online] URL: http://www.hort.cornell.edu/uhi/ research/articles/JArb19(2).pdf

Harris JR, Gilman EF (1993). Production method affects growth and post-transplant establishment of "East Palatka" Holly. Journal of American Society for Horticultural Science 118 (2): 194-200. [online] URL: http://journal.ashspubli cations.org/content/118/2/194.short

Hartmann HT, Kester DE, Davies Jr FT, Geneve $R L$ (2011). Techniques of propagation by cuttings. In: "Hartmann and Kester's plant propagation: principles and practices ( $8^{\text {th }}$ edn)" (Davies FT, Geneve RL, Kester DE eds). Pearson Education Inc., Prentice Hall, NJ, USA, pp. 344415.

Hättenschwiler S, Miglietta F, Raschi A (1997). Morphological adjustment of mature Quercus ilex trees to elevated $\mathrm{CO}_{2}$. Acta Oecologica 18: 361-365. - doi: 10.1016/S1146-609X(97)80026-4

Hensley DL (1993). Harvest method has no influence on growth of transplanted green ash. Journal of Arboriculture 19 (6): 379-382. [online] URL: http://hort.ifas.ufl.edu/woody/docu ments/articles/HDL9301.pdf

Hickman JC (1970). Seasonal course of xylem sap tension. Ecology 51: 1052-1056. - doi: 10.2307/ 1933632

Iannelli R, Bianchi V, Masciandaro G, Ceccanti B, Pretner A (2010). Agricultural reuse of polluted dredged sediments: the AGRIPORT European project. In: Proceedings of the "IWA - XII International Conference of Wetland System for Water Pollution Control" (Bresciani R, Zanieri L eds). Venezia (Italy) 4-7 Oct 2010. Palombi Editori, Roma, Italy, pp. 472-479.

Indorante SJ, Follmer LR, Hammer RD, Koenig PG (1990). Particle size analysis by a modified pipette procedure. Journal of American Soil Science Society 54: 560-563. - doi: 10.2136/sssaj19 $90.03615995005400020047 x$

Jack-Scott EJ (2012). Survival and growth factors affecting community-planted urban street trees. Cities and the Environment 4 (1), Article 10, pp. 16. [online] URL: http://digitalcommons. Imu.edu/cate/vol4/iss1/10

Koeser A, Stewart JR (2008). Effects of transplanting on the growth and survival of nursery stock. HortScience 43 (4): 1239-1239.

Krall JP, Edwards GE (1992). Relationship between photosystem II activity and $\mathrm{CO}_{2}$ fixation in leaves. Physiologia Plantarum 86: 180-187. doi: 10.1111/j.1399-3054.1992.tb01328.x

Kozlowski TT, Davis WJ (1975). Control of water balance in transplanted trees. Journal of Arboriculture 1: 1-10.

Masciandaro G, Doni S, Garcia C, Hernandez MT, Rocchio P, Loza M, Macci C (2015). Innovative technique to recover contaminate driver sediments (CLEANSED LIFE 12ENV/IT/000652). In: Proceedings of the " $15^{\text {th }}$ International Waste Management and Landfill Symposium, Sardinia 2015" (Cossu R, He P, Kjeldsen P, Matsufuji Y, Reinhart D, Stegmann R eds). S. Margherita di Pula (CA, Italy), 5-9 Oct 2015. CISA Publisher, Cagliari, Italy, pp. 477. [online] URL: http:// www.lifecleansed.com/wp-content/uploads/20 15/07/Masciandaro-EN.pdf

McKay HM (1997). A review of the effects of stresses between lifting and planting on nursery stock quality and performance. New forests 13: 369-399. - doi: 10.1023/A:1006563130976 Mena-Petite A, Ortega-Lasuen U, González-Moro MB, Lacuesta M, Muñoz-Rueda A (2001). Storage duration and temperature effect on the functional integrity of container and bare root Pinus radiata D. Don stock-types. Trees 15: 289296. - doi: 10.1007/s004680100104

Murata N, Takahashi S, Nishiyama Y, Allakhverdiev SI (2007). Photoinhibition of photosystem II under environmental stress. Biochimica et Biophysica Acta (BBA) - Bioenergetics 1767 (6): 414-421. - doi: 10.1016/j.bbabio.2006. 11.019

Netzband A, Reincke H, Bergemann M (2002). The river Elbe. Journal of Soils and Sediments 2 (3): 112-116. - doi: 10.1007/BF02988462

Oukarroum A, Schansker G, Strasser RJ (2009). Drought stress effects on photosystem I content and photosystem II thermotolerance analyzed using $\mathrm{Chl}$ a fluorescence kinetics in barley varieties differing in their drought tolerance. Physiologia Plantarum 137: 188-199. - doi: 10.1111/j.1399-3054.2009.01273.x

Rambal S (1992). Quercus ilex facing water stress: a functional equilibrium hypothesis. Plant Ecology 99-100 (1): 147-153. - doi: 10.1007/ 978-94-017-2836-2_15

Reynolds WD, Elrick DE, Youngs EG, Amoozegar A, Booltink HWG, Bouma J (2002). Saturated and field-saturated water flow parameters. In: "Methods of Soil Analysis, Part 4. Physical Methods" (Dane J, Topp C eds). SSSA, Madison, WI, USA, pp. 797-878.

Salomons W, Brils J (2004) Contaminated sediments in European river basins. Project Report,
EU Project EVK1-CT-2001-20002, TNO, The Netherlands, pp. 47. [online] URL: http:// www.htg-baggergut.de/Downloads/SedNet_bo oklet_final.pdf

Strasser RJ, Srivastava A, Tsimilli-Michael M (2000). The fluorescence transient as a tool to characterize and screen photosynthetic samples. In: "Probing Photosynthesis: Mechanisms, Regulation and Adaptation" (Yunus M, Pathre $\mathrm{U}$, Mohanty P eds). Taylor and Francis, London, UK, pp. 445-483. [online] URL: http://www.re searchgate.net/profile/Reto_Strasser/publicati on/252250818

Strasser RJ, Tsimilli-Michael M, Srivastava A (2004). Analysis of the chlorophyll a fluorescence transient. In: "Advances in photosynthesis and respiration series. Chlorophyll fluorescence: A signature of photosynthesis" (Papageorgiou GC, Govindjee eds). Springer, Dordrecht, Netherlands, pp. 321-362. - doi: 10.1007/ 978-1-4020-3218-9_12

Struve DK (2009). Tree establishment: a review of some of the factors affecting transplant survival and establishment. Arboriculture and Urban Forestry 35 (1): 10-13. [online] URL: http://barchampro.co.uk/sites/default/files/stru ve_2009_establishment.pdf

Ugolini F, Calzolari C, Lanini GM, Martelli F, Massetti L, Sabatini F, Ungaro F, Damiano S, Masciandaro MG (2015). Another future for hydro ways sediments. In: Proceedings of the " $15^{\text {th }}$ International Waste Management and Landfill Symposium, Sardinia 2015" (Cossu R, He P, Kjeldsen $P$, Matsufuji $Y$, Reinhart D, Stegmann R eds). S. Margherita di Pula (CA, Italy), 5-9 Oct 2015. CISA Publisher, Cagliari, Italy, pp. 477.

Van Heerden PDR, Swanepoel JW, Krüger GHJ (2007). Modulation of photosynthesis by drought in two desert scrub species exhibiting C3-mode $\mathrm{CO}_{2}$ assimilation. Environmental and Experimental Botany 61: 124-136. - doi: 10.1016/j. envexpbot.2007.05.005

Watson GW, Himelick EB (1997). Principles and practice of planting trees and shrubs. International Society of Arboriculture, Champaign, IL, USA, pp. 200.

Whiting D, O'Meara C (2014). Tree selection: right plant, right place. CMG GardenNotes no. 632, Colorado State University Extension, CO, USA, pp. 10. [online] URL: http://www.ext.colo state.edu/mg/Gardennotes/632.pdf

Yang J, McBride J (2003). A unique technique for street tree planting in Beijing. Arboricultural Journal 27 (1): 1-10. - doi: 10.1080/03071375.20 03.9747358 